\title{
Granulocyte transfusion in treatment of infected neutropenic children
}

\author{
J. GRAHAM POLE, M. DAVIE, I. KERSHAW, D. A. C. BARTER, and \\ M. L. N. WILLOUGHBY \\ From the University Department of Child Health and Department of Haematology, Royal Hospital for Sick \\ Children, Glasgow
}

\begin{abstract}
Graham Pole, J., Davie, M., Kershaw, I., Barter, D. A. C., and Willoughby, M. L. N. (1976). Archives of Disease in Childhood, 51, 521. Granulocyte transfusion in treatment of infected neutropenic children. Thirty episodes of infection in severely neutropenic children with acute leukaemia and aplastic anaemia resistant to antibiotics were treated with a total of 51 granulocyte transfusions, mostly collected from normal donors by means of an Aminco continuous flow cell separator. The mean granulocyte increment in the recipients was $820 / \mathrm{mm}^{3}$ at 1 hour and $307 / \mathrm{mm}^{3}$ at 15 hours post-transfusion and it showed a correlation with the number of cells transfused, the size of the child, and his pretransfusion granulocyte count. Fifteen (50\%) episodes responded clinically by 24 hours and $23(77 \%)$ by 5 days post-transfusion. Two more children recovered more slowly and 5 died. Poor response was associated with multiple-site infections and with a prolonged period of infection before granulocyte transfusion, but the primary diagnosis did not influence the outcome. We conclude that granulocyte transfusion significantly reduces the mortality and morbidity from infection in neutropenic children with acute leukaemia.
\end{abstract}

Severe infection is common in acute leukaemia during periods of bone marrow depression produced by the disease and its treatment (Levine, Graw, and Young, 1972). The incidence of infection correlates with the degree and duration of leucopenia (Bodey et al., 1966) and treatment, even with powerful antibiotic combinations, may be ineffective in the absence of granulocytes (Tattersall, Spiers, and Darrell, 1972). Although infection may be prevented by isolation combined with decontamination with topical antiseptics and nonabsorbed antibiotics (Levine et al., 1973), leukaemia often presents with severe infection before such measures are operative.

Granulocyte transfusion is a logical treatment for such patients. Large numbers of cells can be collected from normal as well as chronic myeloid leukaemic donors, using continuous flow centrifugation (CFC) (Graw et al., 1972; Lowenthal et al., 1975), or filtration leucapheresis (Djerassi et al., 1972; Higby et al., 1975). Controlled

Received 12 November 1975. studies have shown the value of granulocyte transfusions in adults (Graw et al., 1972; Higby et al., 1975) but their place in paediatric practice has not been evaluated. We describe here our experience with granulocyte transfusion in children with infections not responding to other treatment. All had acute leukaemia or aplastic anaemia, were severely neutropenic, and usually lymphopenic and thrombocytopenic also. We have related immediate and later haematological and clinical responses to the nature and duration of infection, the number of granulocytes transfused, and the recipient size and pretransfusion count.

\section{Patients and methods}

Refractory infections in $\mathbf{3 0}$ children were treated with a total of 51 granulocyte transfusions. Twenty-three of the children had acute lymphoblastic leukaemia (ALL), 6 acute myeloblastic leukaemia (AML), and one aplastic anaemia. Eighteen were boys. The average age was $5 \cdot 4$ years (range $1 \cdot 5-14 \cdot 1$ ). Seventeen were in the initial stages of acute leukaemia, many having received no previous antileukaemia therapy. Three patients were given granulocytes collected by single-unit 
$(200 \mathrm{ml})$ leucapheresis of chronic myeloid leukaemic donors. The other 48 transfusions were from normal donors collected with a continuous flow cell separator (Aminco Celltrifuge, Silver Springs, Maryland, U.S.A.). Four were from unrelated normal donors, the other 44 were from the parents.

The cell separator has been described elsewhere (Freireich, Judson, and Levin, 1965; Buckner et al., 1969). The procedure uses a continuous vein-to-vein flow of blood through a rotating bowl that separates the different blood components by centrifugal force. Leucocytes are collected at about $2 \mathrm{ml} / \mathrm{min}$ from the buffy layer at the red cell-plasma interface, and the red cells and plasma recombine for return to the donor. The donor receives $2500-3000$ units heparin as an initial intravenous dose followed by continuous infusion of 40 units $/ \mathrm{min}$. In early runs acid citrate dextrose was infused continuously at $1 \mathrm{ml} / \mathrm{min}$. Latterly hydroxyethyl starch (HES 6\%, McGaw) or dextran (Dextraven 150, Fisons) was infused at $3-6 \mathrm{ml} / \mathrm{min}$ to increase red cell sedimentation and improve the granulocyte concentration of the buffy layer (McCredie et al., 1974; Lowenthal and Park, 1975).

Mean values for CFC leucapheresis were: blood flow $45 \mathrm{ml} / \mathrm{min}$, volume processed 91 , volume collected $440 \mathrm{ml}$, period of collection $3 \frac{1}{4}$ hours. Effects on the donor were minimal: occasional chilling, faintness, and flow problems required rewarming, slowing the run, antihistamine administration, or resiting a cannula. All potential donors were ABO grouped and only those ABO compatible with the recipient were used. Full compatibility was confirmed by formal cross-matching of donor red cells against recipient serum. Donor and recipient were also HLA typed but results were obtained later and did not affect the decision to use a donor. All parental donors have, of course, at least two HLA antigens identical to their children. Donors had pre- and post-leucapheresis full blood counts, capillary clotting times, 12-microanalysis (including plasma electrolytes, urea, creatinine, transaminases, and protein), immunoglobulins, and blood cultures, and were routinely checked for hepatitis antigen, which was negative in all cases. The only abnormality was a mean fall in platelet count of $15 \%$ which had returned to previous levels 12 hours later when checked. It was deliberate policy to collect platelets as well as granulocytes, since most recipients were both neutropenic and thrombocytopenic.

The leucocytes were collected into Fenwal bags containing acid citrate dextrose and sealed immediately. A Coulter white cell counter and Leishman-stained films were used during the run to monitor the number and proportions of leucocytes, adjusting the buffy position to improve yield. The cells were routinely irradiated to 1500 rads with a Siemens $300-\mathrm{Kv}$ machine to avoid engraftment of transfused cells and the risk of graft versus host disease (Graw et al., 1970). The phagocytic and bactericidal capacity of granulocytes were tested by standard techniques (Miller, 1969; Solberg and Hellum, 1972) and found to be normal in several experiments. The cells were transfused rapidly over 1 to 3 hours via platelet-giving sets (Fenwal).
Recipients were given chlorpheniramine $10 \mathrm{mg}$ intravenously at the start and those under 6 years of age also received frusemide $10 \mathrm{mg}$ to prevent volume overload, since we wanted to transfuse the cells rapidly.

The infections were divided into (1) proved septicaemia; (2) pneumonia; (3) cellulitis (abscesses, skin, and mucosal infections); (4) others (suspected septicaemias, meningitis, pyelonephritis, and undiagnosed fevers). Antibiotics, usually either gentamicin and cloxacillin or a 5-antibiotic combination (Hammersmith regimen; Tattersall et al., 1972) 6-hourly intravenously, were started empirically after culturing blood, urine, stool, and swabs from infected sites and taking $x$-ray films.

Patients received granulocyte transfusions if they had infections associated with severe neutropenia ( $<$ $300 / \mathrm{mm}^{3}$ ) not responding to antibiotics after a mean period of 72 hours. Intravenous antibiotics were continued in the first instance for 5 days, modified according to results of cultures. The clinical state of the children was assessed 24 hours and 5 days after transfusion, and they were considered well if a normal temperature was maintained together with clearing of clinical signs of infection. No control patients were studied for comparison. Full blood counts were done on capillary samples from children before and at 1 hour and about 15 hours after transfusion.

Student's ' $t$ ' test was used for statistical analysis of results.

\section{Results}

Clinical evaluation. Table I shows 31 pathogens isolated from the 30 children. Grampositive bacteria were causative or contributory in 12 cases and Gram-negative in 10. Five out of 7 children who responded poorly to granulocyte transfusion had Gram-negative septicaemia, and 2 of these also had fungal infections. Several children had more than one organism isolated, fungi being cultured chiefly from sputum and gastrointestinal tract. No organism was cultured from 9 febrile children, all of whom recovered after transfusion.

TABLE I

\section{Pathogens isolated from granulocyte recipients}

\begin{tabular}{l|c}
\multicolumn{1}{c|}{ Pathogen } & $\begin{array}{c}\text { No. of } \\
\text { patients }\end{array}$ \\
\hline Staphylococcus aureus & 8 \\
Candida albicans & 7 \\
Esch. coli & 4 \\
Streptococcus pyogenes, faecalis, pneumoniae & 4 \\
Haemophilus influenzae & 2 \\
Klebsiella aerogenes & 2 \\
Aspergillus & 2 \\
Pseudomonas pyocyanea & 1 \\
Proteus mirabilis & 1 \\
\hline \multicolumn{1}{c}{ Total } & 31 \\
\hline
\end{tabular}


Table II shows the overall clinical response rate at 24 hours and at 5 days. Granulocyte transfusion is difficult to evaluate clinically and subject to observer bias. We have used 'response' to indicate resolution of fever, but other signs, particularly of toxicity and shock, were assessed. On this basis 15 children $(50 \%)$ were well by 24 hours and 23 $(77 \%)$ by 5 days, and similar response rates were seen in ALL and AML patients. Response, however, was related to the type of infection (Table III). Patients with pneumonia fared better than those with septicaemia, particularly when there were multiple sites of infection (for example, septicaemia plus meningitis plus cellulitis). Three patients with pneumonia developed temporary respiratory

TABLE II

Clinical response related to primary diagnosis

\begin{tabular}{|c|c|c|c|}
\hline & \multicolumn{3}{|c|}{ No. (\%) with clinical response at: } \\
\hline & 24 hours & & lays \\
\hline $\begin{array}{c}\text { Acute lymphoblastic } \\
\text { leukaemia }(n=23) \\
\text { Acute myeloblastic } \\
\text { leukaemia }(n=6) \\
\text { Aplastic anaemia }(n=1)\end{array}$ & $\begin{array}{ll}12 & (52) \\
3 & (50) \\
0 & \end{array}$ & $\begin{array}{r}18 \\
5 \\
0\end{array}$ & $\begin{array}{l}(79) \\
(83)\end{array}$ \\
\hline Total & $15 \quad(50)$ & 23 & (77) \\
\hline
\end{tabular}

TABLE III

Clinical response related to type of infection

\begin{tabular}{lr|rr|rr}
\hline \multicolumn{2}{c}{$\begin{array}{c}\text { Type of infection } \\
\text { and no. of patients }\end{array}$} & \multicolumn{3}{c|}{ No. (\%) well at: } \\
\cline { 3 - 6 } & & \multicolumn{2}{c|}{24 hours } & \multicolumn{2}{c}{5 days } \\
\hline Septicaemia & 14 & 5 & $(35)$ & 8 & $(56)$ \\
Pneumonia & 10 & 6 & $(60)$ & 8 & $(80)$ \\
Cellulitis & 8 & 3 & $(37)$ & 6 & $(75)$ \\
Suspected septicaemia & 4 & 3 & $(75)$ & 4 & $(100)$ \\
Pyelonephritis & 2 & 2 & $(100)$ & 2 & $(100)$ \\
Meningitis & 2 & 0 & & 0 & $(50)$ \\
Multiple sites & 10 & 5 & $(50)$ & 5 & $(50)$ \\
\hline \multicolumn{1}{c}{ Total } & 30 & 15 & $(50)$ & 23 & $(77)$ \\
\end{tabular}

* Cellulitis 4, pneumonia 3, meningitis 2 , pyelonephritis 1.

distress during transfusion, which may have been due to pulmonary sequestration of transfused cells, as has been reported by others (Vallejos et al., 1975). Five children died, 4 with Gram-negative septicaemia, but bacterial cultures of blood and cerebrospinal fluid mostly became sterile before death.

Granulocyte transfusion had an antipyretic effect in most cases. Mean body temperatures $( \pm 1 \mathrm{SD})$ were $38 \cdot 5 \pm 0.9$ before and $37 \cdot 7 \pm 0 \cdot 824$ hours after transfusion $(P<0.01)$. A short-lived rise in temperature accompanied 3 transfusions; leucocyte antibodies were not detected. Fig. 1 shows clinical

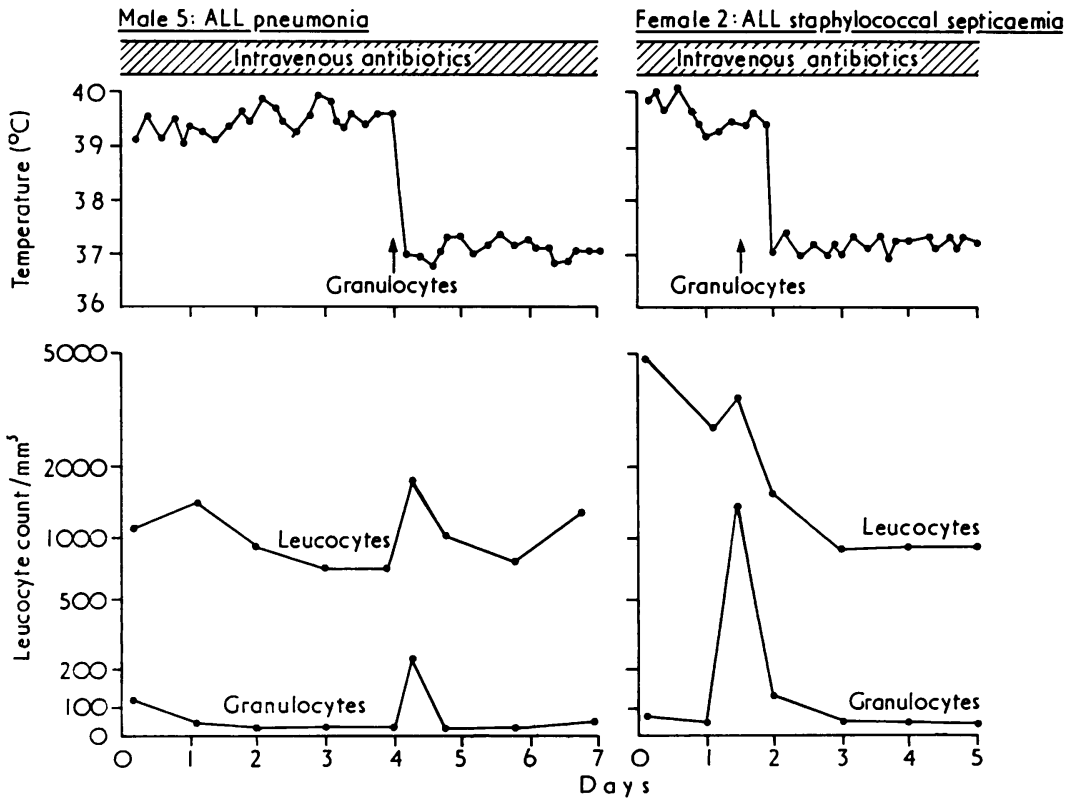

FIG. 1.-Clinical response to granulocyte transfusion in 2 children with refractory infections. 
TABLE IV

23 clinical responders compared with 7 non-responders (mean values)

\begin{tabular}{|c|c|c|c|c|c|c|c|c|c|}
\hline & \multirow{2}{*}{$\begin{array}{c}\text { Age } / \text { surface } \\
\text { area } \\
\text { (years } / \mathrm{m}^{2} \text { ) }\end{array}$} & \multicolumn{2}{|c|}{$\begin{array}{l}\text { Pretransfusion } \\
\text { days of: }\end{array}$} & \multirow{2}{*}{$\begin{array}{c}>1 \\
\text { Infection } \\
\text { site/ } \\
\text { organism }\end{array}$} & \multirow{2}{*}{$\begin{array}{c}\text { Primary } \\
\text { diagnosis } \\
\text { not } \\
\text { ALL }\end{array}$} & \multirow{2}{*}{$\begin{array}{c}\text { No. } \\
\text { of } \\
\text { transfusions }\end{array}$} & \multirow{2}{*}{$\begin{array}{c}\text { Pretrans- } \\
\text { fusion } \\
\text { granulocyte } \\
\text { count } \\
\left(/ \mathrm{mm}^{3}\right)\end{array}$} & \multirow{2}{*}{$\begin{array}{c}\text { 1-hour } \\
\text { increment } \\
\left(/ \mathrm{mm}^{3}\right)\end{array}$} & \multirow{2}{*}{$\begin{array}{c}\text { 15-hour } \\
\text { incremen } \\
\left(/ \mathrm{mm}^{3}\right)\end{array}$} \\
\hline & & Fever & $\begin{array}{l}\text { Anti- } \\
\text { biotics }\end{array}$ & & & & & & \\
\hline $\begin{array}{l}\text { Responders } \\
\text { Non-responders }\end{array}$ & $\begin{array}{l}4 \cdot 9 / 0 \cdot 7 \\
5 \cdot 8 / 0 \cdot 78\end{array}$ & $\begin{array}{l}3 \cdot 5 \\
7 \cdot 5\end{array}$ & $\begin{array}{l}2 \cdot 5 \\
5 \cdot 0\end{array}$ & $\begin{array}{l}5 / 23 \\
5 / 7\end{array}$ & $\begin{array}{l}5 / 23 \\
2 / 7\end{array}$ & $\begin{array}{l}1 \cdot 4 \\
2 \cdot 4\end{array}$ & $\begin{array}{r}63 \\
195\end{array}$ & $\begin{array}{l}728 \\
780\end{array}$ & $\begin{array}{l}365 \\
151\end{array}$ \\
\hline
\end{tabular}

Last four columns are means for all granulocyte transfusions: mean granulocytes per transfusion were $1.52 \times 10^{10}$ for responders, $1.92 \times 10^{10}$ for non-responders.

responses in two neutropenic children with pneumonia and with septicaemia complicating ALL.

Table IV compares the 7 infections that responded poorly to transfusion with the 23 that responded well. Non-response was associated with significantly more days of fever $(P<0.02)$ and of antibiotic administration $(P<0.05)$ pretransfusion and with more multiple infections. Also, the nonresponders had distinctly poorer 15 -hour posttransfusion granulocyte increments $(P<0 \cdot 10)$, implying rapid utilization or sequestration of transfused cells. Five non-responders had ALL, $1 \mathrm{AML}$, and 1 aplastic anaemia.

Haematological evaluation. Fig. $2^{\star}$ shows the mean leucocyte, granulocyte, and platelet counts before, 1 hour after, and about 15 hours (the following morning) after transfusion. The mean granulocyte increments were $820 / \mathrm{mm}^{3}$ at 1 hour and $307 / \mathrm{mm}^{3}$ at 15 hours. Fifteen children had pretransfusion granulocyte counts of zero before their first transfusion. Rises in platelet count were often more sustained (mean increments $24000 / \mathrm{mm}^{3}$ at 1 hour and $27000 / \mathrm{mm}^{3}$ at 15 hours).

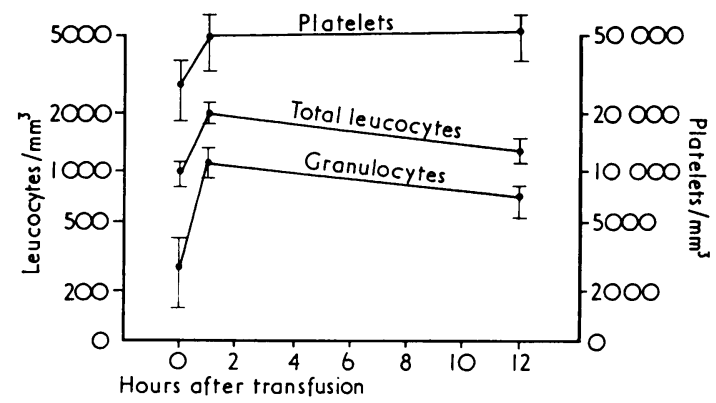

FIG. 2.-Leucocyte, granulocyte, and platelet counts (mean $\pm S E M)$ before, 1 hour after, and 15 hours after transfusion.

^ Figs. 2-5 are plotted on a logarithmic scale.
Post-transfusion granulocyte increments were related to a number of factors. Adding erythrocyte-sedimenting agents to the flow-path during leucapheresis improves definition and allows more granulocytes to be collected with less erythrocyte contamination (McCredie et al., 1974; Lowenthal and Park, 1975). The average granulocyte collection was $2.04 \times 10^{10}$ with dextran or hydroxyethyl starch, and $0.77 \times 10^{10}$ without $(t=5 \cdot 48, P<$ $0.001)$, and was reflected in significantly higher 1-hour and 15-hour granulocyte increments in recipients (Fig. 3). Children with blood volumes of 21 or less $\left(\leqslant 0.8 \mathrm{~m}^{2}\right)$ had significantly better 1-hour increments than larger children (Fig. 4). Also children with granulocyte counts $>100 / \mathrm{mm}^{3}$ before transfusion had significantly better 1-hour increments than those with lower pretransfusion counts (Fig. 5). Granulocyte increments were unrelated to HLA matching of parents and children, no significant differences being found for 0,1 , and 2 donor-recipient mismatches.

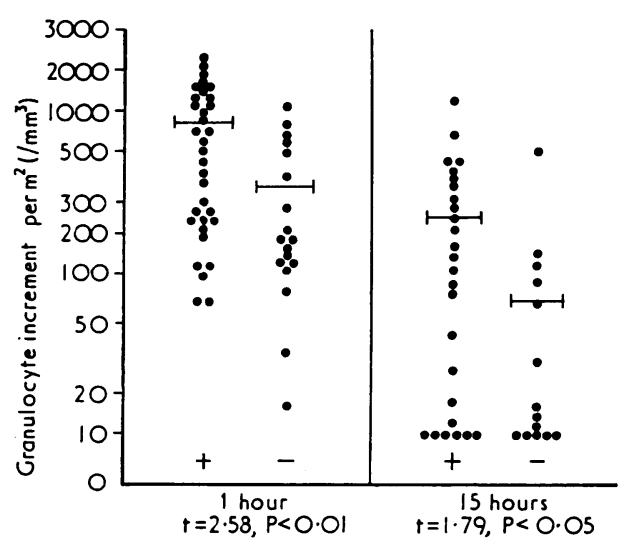

Fig. 3.-1-hour and 15-hour granulocyte increments related to $(+$ or -$) R B C$-sedimenting agents. Horizontal bars represent means. Corrected for surface area. 


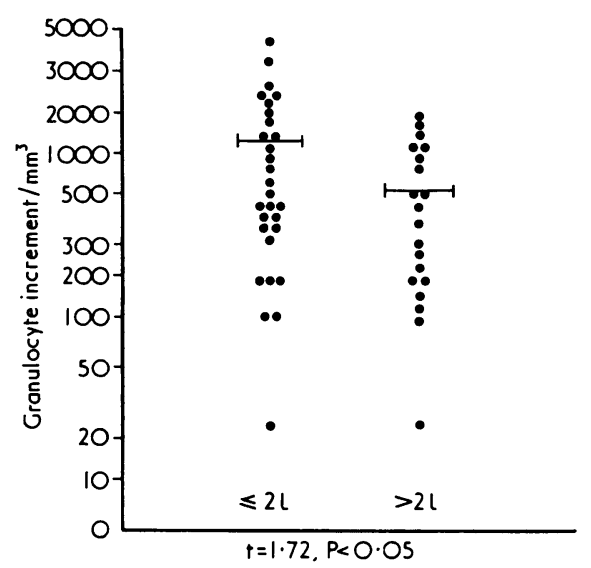

FIG. 4.-1-hour granulocyte increment related to recipient blood volume.

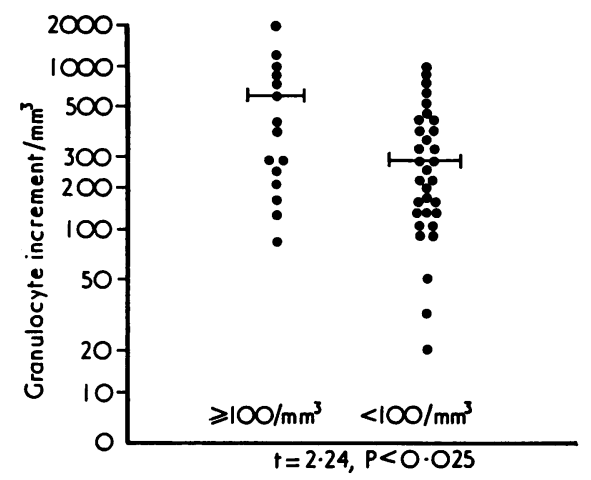

FIG. 5.-1-hour granulocyte increment related to pretransfusion recipient count. (Corrected for recipient surface area and cells transfused.)

Granulocyte utilization. Probably the more depleted the granulocyte stores the more rapidly transfused cells are utilized and leave the circulation (Fig. 5). The presence of donor granulocytes was sought in samples from bone marrow and from infected skin lesions and cerebrospinal fluid (CSF). No excess of leucocytes with male karyotype were detected in a girl 1 day and 10 days after receiving a leucocyte transfusion from her father. Smears taken from sites of skin or mucosal sepsis, however, often showed an influx of granulocytes within a few hours of transfusion. Fig. 6 shows the course of a neutropenic child with Esch. coli septicaemia and meningitis. Twelve hours after each of 2 transfusions the peripheral blood granulocyte count had returned to zero, but granulocytes appeared for the first time in

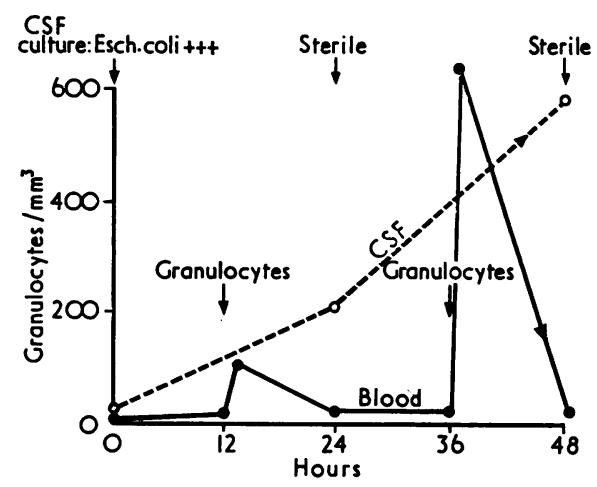

FIG. 6.-Effect of 2 granulocyte transfusions in Esch. coli septicaemia and meningitis.

the CSF 12 hours after the first transfusion $\left(200 / \mathrm{mm}^{3}\right)$ rising to $560 / \mathrm{mm}^{3} 12$ hours after the second, at which time only a few dead phagocytosed Esch. coli organisms remained in the CSF.

\section{Discussion}

Infection is the major cause of death in acute leukaemia (Hersch et al., 1965; Levine et al., 1972), and several reports have shown the value of granulocyte transfusions in treating neutropenic adults with refractory infections (Graw et al., 1972; Lowenthal et al., 1975; Higby et al., 1975). There has been no separate analysis of their use in leukaemic children and there are several reasons why this should be done. (1) Their long-term prognosis is much better than in adults. At least $50 \%$ of children with ALL should achieve prolonged survival or cure (British Medical Journal, 1975), so that death from infection is particularly tragic. (2) Infections often progress more rapidly in such children. They are often refractory to antibiotic treatment and there is a significant mortality. (3) The small size of the child relative to the adult donor gives him an innate advantage in terms of leucocyte yield and increment.

Twenty-five of our 30 infections were successfully treated, owing in $23(77 \%)$ wholly or partly to granulocyte transfusion (Table II). These results compare favourably with mainly adult series in whom typical response rates have been between $46 \%$ and $67 \%$ (Graw et al., 1972; Lowenthal et al., 1975; Schwarzenberg, Schneider, and Mathé, 1975; Vallejos et al., 1975), though a recent controlled trial of granulocyte transfusions produced a $90 \%$ positive response (Higby et al., 1975). Also adult patients need several transfusions for reliable response (Lowenthal et al., 1975; Higby et al., 1975), 
while many of our patients responded to single transfusions. These good and often rapid responses in children may be due to their smaller blood volume, their primary diagnosis (most often ALL, while most adults have had AML), and possibly their greater capacity to respond to treatment, particularly when compared to the elderly.

Four of the 5 children who died had Gramnegative bacterial infections complicating newly diagnosed ALL. As they were referred from other hospitals the interval between developing infection and receiving granulocytes was often prolonged (Table IV) and three had started antileukaemic therapy. Children with infections at the time of diagnosis should receive vigorous anti-infective measures before starting any immunosuppressive therapy, ideally using granulocyte transfusion if there is not a clear-cut response to antibiotics within 48 hours.

Granulocyte increments were related to several factors-namely, number of cells transfused, recipient blood volume, and pretransfusion count. Closeness of HLA matching did not seem important, contrary to other reports (Graw et al., 1972; Mishler et al., 1975), though most of our donors were parents and therefore identical with the recipients at at least two HLA antigenic sites. Both granulocyte and platelet counts rose significantly after transfusion and often remained above their basal level 15 hours later (Fig. 2). Platelet counts were often higher at 15 hours than 1 hour, probably because of control of infection as well as close donor-recipient compatibility. Red cell sedimentation effectively increased the granulocyte yield and subsequent increment, as previously reported (McCredie et al., 1974; Lowenthal and Park, 1975), and reduced the plasma and red cell load to the child. Though smaller children had significantly higher increments, there was considerable overlap between patients above and below 2 litres blood volume. More marked differences were seen between children with pretransfusion granulocyte counts above and below $100 / \mathrm{mm}^{3}$, as reported in adults (Freireich et al., 1964; Vallejos et al., 1975). A pretransfusion count below $100 / \mathrm{mm}^{3}$ reflects profound depletion of granulocyte reserves by infection superimposed on bone marrow failure, and increments are presumably small because of rapid passage of transfused cells to sites of infection. One should not overemphasize peripheral blood changes, but good 1-hour and 15-hour increments probably indicate a satisfactory supply of granulocytes to infected tissues and are a useful index of response. Certainly the responders had a higher 15-hour increment than the nonresponders.
Neutropenic patients often fail to produce typical infective lesions and the appearance of pus cells at sites of infection (Fig. 6) is also a favourable sign.

Most of our patients recovered completely after granulocyte transfusions, though without a control group their efficacy cannot be proved. Controlled studies in adults have, however, shown significant benefit both in defervescence and survival (Graw et al., 1972; Higby et al., 1975), and a controlled trial would be impracticable in a single paediatric centre. The infections we encounter in neutropenic leukaemic children are often refractory to oral antibiotics, may respond to intravenous antibiotic combinations, but often require granulocyte transfusions to be added. Without their use the mortality in our patients would probably have been significantly higher and most infections would have run a more protracted course, causing further delay in specific antileukaemic therapy.

We thank Professor J. H. Hutchison and Dr. R. A. Shanks for allowing us to report patients under their care; Dr. H. Simpson, Royal Hospital for Sick Children, Edinburgh, and Drs. W. Walker and T. Noble, Royal Victoria Infirmary, Newcastle, for providing clinical details of their patients; the laboratory and nursing staff of the Royal Hospital for Sick Children; and the Department of Radiotherapy, Western Infirmary, for irradiating the cells. Tenovus (Scotland) met a large part of the cost of the cell separator. One of us (D.A.C.B.) holds a David Cargill Trust fellowship in paediatric oncology.

\section{REFERENCES}

Bodey, G. P., Buckley, M., Sathe, Y. S., and Freireich, E. J. (1966). Quantitative relationships between circulating leucocytes and infection in patients with acute leukemia. Annals of Internal Medicine, 64, 328.

British Medical fournal (1975). Long survival from acute leukemia in childhood, 1,111 .

Buckner, C. D., Graw, R. G., Eisel, R. J., Henderson, E. S., and Perry, S. (1969). Leukapheresis by continuous flow centrifugation (CFC) in patients with chronic myelocytic leukemia (CML). Blood, 33, 353.

Djerassi, I., Kim, J. S., Suvansri, U., Mitrakul, C., and Ciesielka, W. (1972). Continuous flow filtration leukopheresis. Transfusion, $12,75$.

Freireich, E. J., Judson, G., and Levin, R. H. (1965). Separation and collection of leukocytes. Cancer Research, 25, 1516.

Freireich, E. J., Levin, R. H., Whang, J., Carbone, P. P., Bronson, W., and Morse, E. E. (1964). The function and fate of transfused leukocytes from donors with chronic myelocytic leukemia in leucopenic recipients. Annals of the New York Academy of Sciences, 113, 1081

Graw, R. G., Herzig, G., Perry, S., and Henderson, E. S. (1972) Normal granulocyte transfusion therapy: treatment of septicemia due to gram-negative bacteria. New England fournal of Medicine, 287, 367.

Graw, R. G., Buckner, C. D., Whang-Peng, J., Leventhal, B. G., Krüger, G., Berard, C., and Henderson, E. S. (1970). Complication of bone marrow transplantation: graft-versus-host disease resulting from chronic-myelogenous-leukaemia leucocyte transfusions. Lancet, $2,338$.

Hersh, E. M., Bodey, G. P., Nies, B. A., and Freireich, E. J. (1965). Causes of death in acute leukemia. Fournal of the American Medical Association, 193, 105. 
Higby, D. J., Yates, J. W., Henderson, E. S., and Holland, J. F. (1975). Filtration leukapheresis for granulocyte transfusion therapy: clinical and laboratory studies. New England fournal of Medicine, 292, 761.

Levine, A. S., Graw, R. G., and Young, R. C. (1972). Management of infections in patients with leukemia and lymphoma: current concepts and experimental approaches. Seminars in Hematology, 9,141 .

Levine, A. S., Siegel, S. E., Schreiber, A. D., Hauser, J., Preisler, H., Goldstein, I. M., Siedler, F., Simon, R., Perry, S., Bennett, J. E., and Henderson, E. S. (1973). Protected environments and prophylactic antibiotics. A prospective controlled study of their utility in the therapy of acute leukaemia. New England Fournal of Medicine, 288, 477.

Lowenthal, R. M., and Park, D. S. (1975). The use of Dextran as an adjunct to granulocyte collection with the continuous flow blood cell separator. Transfusion, 15, 23.

Lowenthal, R. M., Grossman, L., Goldman, J. M., Storring, R. A. Buskard, N. A., Park, D. S., Murphy, B. C., Spiers, A. S. D., and Galton, D. A. G. (1975). Granulocyte transfusions in treatment of infections in patients with acute leukaemia and aplastic anaemia. Lancet, 1, 353.

McCredie, K. B., Freireich, E. J., Hester, J. P., and Vallejos, C. (1974). Increased granulocyte collection with the blood cell separator and the addition of Etiocholanolone and Hydroxyethyl starch. Transfusion, 14, 357.
Miller, M. E. (1969). Phagocytosis in the newborn infant: humoral and cellular factors. Fournal of Pediatrics, 74, 255.

Mishler, J. M., Higby, D. J., Cohen, E., Rhomberg, W., Nicora, R. W., and Holland, J. F. (1975). Evaluation of donorrecipient serological discordance and effectiveness of granulocyte replacement therapy. Leucocytes: Separation, Collection and Transfusion. Ed. by J. M. Goldman and R. M. Lowenthal, p. 427. Academic Press, London.

Schwarzenberg, L., Schneider, M., and Mathé, G. (1975). Factors influencing the clinical response to white blood cell transfusions in aplastic infected patients. Leucocytes: Separation, Collection and Transfusion. Ed. by J. M. Goldman and R. M. Lowenthal, p. 380. Academic Press, London.

Solberg, C. O., and Hellum, K. B. (1972). Neutrophil granulocyte function in bacterial infections. Lancet, $2,727$.

Tattersall, M. H. N., Spiers, A. S. D., and Darrell, J. H. (1972). Initial therapy with combination of five antibiotics in febrile patients with leukaemia and neutropenia. Lancet, 1, 162.

Vallejos, C., McCredie, K. B., Bodey, G. P., Hester, J. P., and Freireich, E. J. (1975). White blood cell transfusions for control of infections in neutropenic patients. Transfusion, 15, 28.

Correspondence to Dr. J. Graham Pole, Royal Hospital for Sick Children, Yorkhill, Glasgow G3 8SJ. 